\title{
Association of early tracheostomy with the mortality and complications of adult patients in intensive care unit
}

\author{
MF Aguilar Arzapalo ${ }^{1 *}$, VL Avendaño², AM Escalante², J Gongora Mukul², MA Cetina Camara², \\ L Soberanes Ramirez', YucaCrit
}

From ESICM LIVES 2015

Berlin, Germany. 3-7 October 2015

\section{Introduction}

Prolonged intubation has been associated with increased mortality and morbidity of patients in critical condition. There is debate over whether early tracheostomy within 7 days, should be or not performed during the stay in the intensive care unit and its relationship with improvement in mortality and morbidity at discharge and 28 days. Recently, a large controlled clinical trial to determine that there is no difference between early or late tracheostomy. However a subsequent meta-analysis determined that if there is improvement in the realization of early tracheostomy.

\section{Objectives}

Determine if there is association between the realization of early tracheostomy in the mortality and complications of adult patients in the intensive care unit at discharge and 28 days.

\section{Methods}

Historical cohort study of risk and association. Data were retrospectively collected for consecutive adult patients admitted to Agustin O'Horan Hospital ICU Merida Mexico, between January 2011 and July 2014, who underwent inpatient medical treatment using electronic files.

\section{Results}

The dataset consisted of 936 medical files, 853 being eligible. Early tracheostomy was quite common, with an incidence of $49.2 \%$. Patients were propensity matched based on their association with death and early

${ }^{1}$ Universidad Autónoma de Yucatan, Critical Care Department, Mérida, Mexico

Full list of author information is available at the end of the article tracheostomy. Of the 853 patients collected, patients with early tracheostomy after admission $(n=419$, $49.2 \%)$, and late tracheostomy $(\mathrm{n}=434,50.8 \%)$ were matched in two groups. These two groups were well balanced with respect to all variables collected. The early tracheostomy group had at decreased risk of mortality at ICU discharge, relative risk ratio: 0.78 ; 95\% CI (0.78-.97) with a decreased risk of $22 \%$ vs the late tracheostomy group who had a increase risk of death at ICU discharge, relative risk ratio: 1.15 ; 95\% CI (1.05-1.17). No significant differences in mortality were found at 28 days and no diferences in complications. Early tracheostomy was associated with decreased mortality whitout additional complications; this association was statistically important.

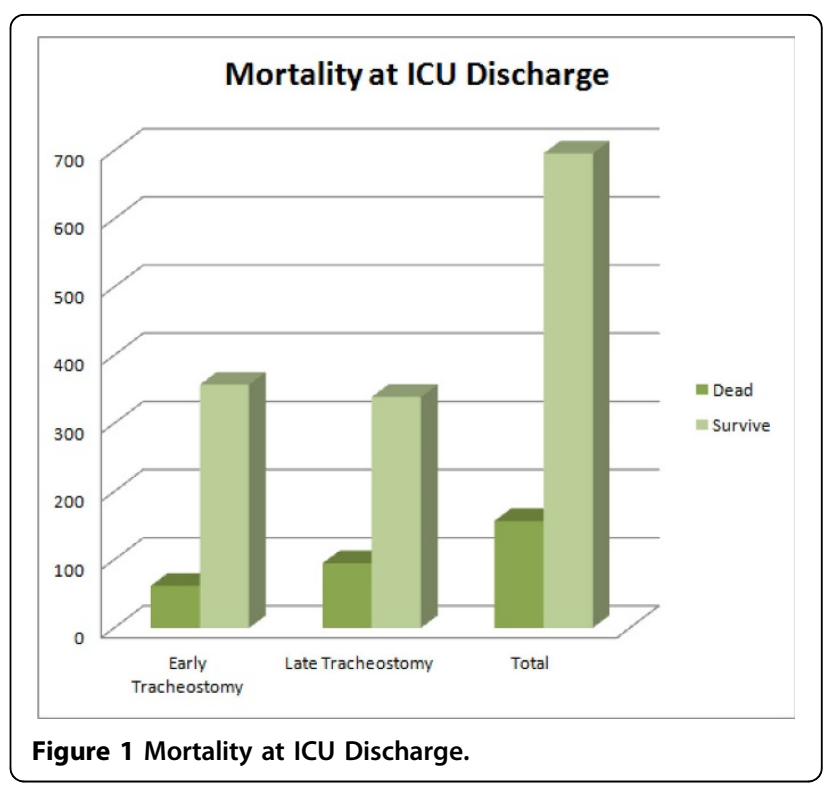




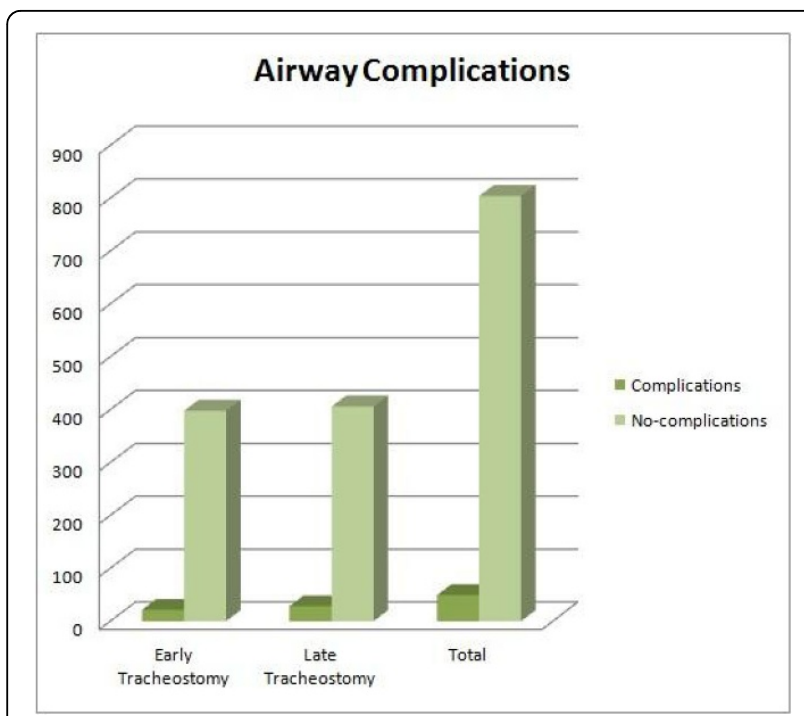

Figure 2 Airway Complications.

\section{Conclusions}

This retrospective cohort trial demonstrates an association between early tracheostomy and better ICU outcome (mortality). Additional studies are required to demonstrate a causal relationship between these variables.

\section{Grant Acknowledgment}

To medical research department of OHoran Hospital

\section{Authors' details}

'Universidad Autónoma de Yucatan, Critical Care Department, Mérida,

Mexico. ${ }^{2}$ Universidad Autónoma de Yucatan, Mérida, Mexico.

Published: 1 October 2015

\section{References}

1. Cox CE, Carson SS, Holmes GM, Howard A, Carey TS: Increase in tracheostomy for prolonged mechanical ventilation in North Carolina, 1993-2002. Crit Care Med 2004, 32:2219-2226.

2. Combes A, Luyt CE, Nieszkowska A, Trouillet JL, Gibert C, Chastre J: Is tracheostomy associated with better outcomes for patients requiring long-term mechanical ventilation? Crit Care Med 2007, 35:802-8073.

3. Young D, Harrison DA, Cuthbertson BH, Rowan K: Effect of Early vs Late Tracheostomy Placement on Survival in Patients Receiving Mechanical Ventilation: The TracMan Randomized Trial. JAMA 2013, 309(20):2121-2129.

doi:10.1186/2197-425X-3-S1-A673

Cite this article as: Aguilar Arzapalo et al: Association of early tracheostomy with the mortality and complications of adult patients in intensive care unit. Intensive Care Medicine Experimental 2015 3(Suppl 1): A673.

\section{Submit your manuscript to a SpringerOpen ${ }^{\mathcal{O}}$ journal and benefit from:}

- Convenient online submission

- Rigorous peer review

- Immediate publication on acceptance

- Open access: articles freely available online

- High visibility within the field

- Retaining the copyright to your article 